\title{
Designing in the Cultural Rural Landscape. A Teaching Opportunity to Experiment a Research-by-Design Process Applied to an Italian UNESCO Wine Site
}

\author{
Catherine Dezio ${ }^{1 *}$, Can Zhang ${ }^{2}$, Yilan Zhang ${ }^{2}$, Davide Marino ${ }^{3}$ \\ 1 Department of Architecture and Urban Studies, Politecnico di Milano, Italy; catherine.dezio@polimi.it \\ 2 Independent researcher \\ 3 Department of Bioscience and Territory, Università del Molise, Italy; dmarino@unimol.it \\ * Correspondence: Catherine.dezio@polimi.it
}

\begin{abstract}
Rural landscapes all over the world are subject to great transformations, first of all the continuous and slow depopulation of land and villages. It is a dramatic phenomenon that causes devastating consequences for environmental systems and for the tangible and intangible heritage of entire territories. The situation becomes more ambiguous when it comes to cultural landscapes, especially those internationally recognized as exceptional (i.e. inscribed on the UNESCO World Heritage List). In this case, the risk is to abandon agricultural production in favor of consumerist tourist economies, which can damage the territorial authenticity. In this paper we question the role of the landscape project in strengthening territorial resilience. In particular, a composite and interdependent action is proposed between landscape design and implementation of a multifunctional agriculture model, oriented towards teaching and tourism. To undertake this investigation, a master's thesis work on Landscape Architecture is examined, as an opportunity for a research-by-design method. The application case is the Italian UNESCO site of Vignale Monferrato, a depopulated rural village, characterized by abandoned land and buildings. The paper concludes by outlining replicability application scenarios for the proposed model.
\end{abstract}

Keywords: landscape design and planning; research-by-design; multifunctional agriculture

\section{Introduction}

In 1992 the World Heritage Committee decided to define a separate category in the World Heritage List that recognizes cultural landscapes [1]. The definition was actually born much earlier, when during the twentieth century various landscape scholars (geographers, urban planners, sociologists) recognized in some rural territories a harmonious balance in the relationship between environmental systems and the anthropogenic components, thanks to which the territories remain such, while adapting to the transformations of the time $[2,3,4,5,6,7,8]$. It is for this characteristic of adaptation to the events that overwhelm them, respecting the constituent and structuring elements, that they are often taken into consideration as resilient systems [7, 8, 9, 10, 11, 12, 13, 14]. In particular, Barbera et al. have seen prototypes of resilient socio-ecological systems in the cultural category of traditional agricultural landscapes, tracing an evaluation method for the characters that make them so [7].

However, what escapes is a strong ambivalence between their constituent structure, which is inherently resilient, and the tendency to fragility $[7,8,13,14]$. Also here, rural areas are under considerable pressure, some of these are: soil consumption, intensification and monospecificity, the presence of pesticides in water, as well as the abandonment of agriculture and related assets $[15,16]$. We know that a cultural rural landscape is resilient as long as the community persists in keeping the methods that forged it productive. The problem arises when the community abandons it, interrupts its production and therefore 
also its care, with consequent environmental problems (hydrogeological), cultural problems (loss of tangible and intangible assets) and socioeconomic problems (loss of attractive economies identifying the surrounding territory risks). All this is possible in cultural landscapes and in ordinary ones, because many rural systems around the world are subject to continuous depopulation $[15,16]$.

There are numerous policies, projects, strategies, ideas concerning the possible regeneration of marginal territories in depopulation. In Italy, the National Strategy of Inner Areas [17] promoted by the Italian government, as a cohesion policy, provided the opportunity to bring back to the center of political and academic debates territories that had remained on the margins for a long time, with a view it differs from simple welfare subsidies, and instead promotes initiative and local growth.

In UNESCO sites the situation is more ambiguous. On one hand, they are still marginal areas, subject to depopulation, but on the other, tourism is growing. The risk is to change the productive territorial identity (which is the same for which tourists are attracted) in favor of purely consumerist commercial economies.

A new vision is needed for cultural rural landscapes, which abandons the principle of conservation as freezing and takes the opportunities and stimuli for a sustainable development of a new agriculture.

In this paper, we will try to investigate the role of the landscape design project within an innovative multifunctional agriculture model, which maintains the traditional quality production (and therefore also the landscape and the authenticity of the territory), inserting integrative activities that support local economy, and generates value through a public rural space integrated into the local and supra-local system. In particular, local resources are enhanced (according to the SNAI guidelines for inner areas), restoring the production of abandoned land, recovering disused buildings, generating jobs for local people and providing opportunities for inclusion between tourists and residents. It will be an antifragile landscape design project, able to dialogue with different policies, actors and governance systems.

It is a model of a resilient regenerative agriculture, which becomes not only local action but also territorial action. It is local because it restores production and integrates alternative activities. It is super-local because it fits in an integrated way in the village and with the rest of the region, thanks to a project of spaces and routes. It is a model that implies a two-way vision between innovation and conservation, and between project and policies, that can generate experimental and stimulating research opportunities, aimed at replicability on others marginal territories.

To analyze this issue, we opted for an application on a known case study, such as the wine-growing site of the Langhe in Italy, with particular reference to the village, in the process of depopulation and aging, of Vignale Monferrato.

To carry out the idea it was decided to work on a master's thesis of the Landscape Architecture Degree of the Polytechnic of Milan, Italy [18]. This choice was not made by chance, but derives from the idea of experiment the teaching method as a meeting point between research and real application. The paper is divided into: materials and methods (section 2), which describes the applied approach, the analytical case studies and the application case study that leads to the definition of the model; results (section 3) with the illustration of the project; discussion (section 4) with the interpretation of the results; conclusions (section 5) with the identification of scenarios and possible guidelines for new future developments on the theme of rural landscapes, from an antifragile, regenerative and resilient perspective. 


\section{Materials and Methods}

\subsection{Approach and method adopted.}

The approach adopted in this work draws on the school of research-by-design, which refers in part to the movement of landscape urbanism, but also has more distant roots [19]. This method implies a project that is not only action but also a real cognitive process, made up of mechanisms of composition and decomposition and identification of possible future scenarios according to the many external variants. The design process itself constitutes the method and innovation.

Teaching and working with students are used in research-by-design not for a coincidence. The didactic process, proposed here as a process of shared knowledge building, represents a precious opportunity to undertake an experimental research path. In this case, there is the opportunity to build a structured and conscious methodology of action on the territory, in which each step is explained and understood with awareness of the diachronic and spatial implications.

The teaching process is based on case studies, which represent important learning and research opportunities. On one hand, the analytical case studies are useful to deconstruct the logic that generated them and to extrapolate positive and negative aspects, elements of replicability and lines of development. Avoiding the effect of compiling data collection, it is a useful exercise for students to understand how the project must precede a research and study phase aimed at developing and building a critical and constructive point of view.

On the other hand, the application case study represents an opportunity to apply the hypothesized strategy, with related considerations in terms of possible "what if" scenarios. As part of this phase, the methods and tools adopted are many, but all are based on a strong anchoring to the historical and traditional, tangible and intangible roots and traces of the place, in line with a European approach to the territory. In the current case of the historical rural landscape, we will talk about historical traces that actually coincide with the ecological ones. For example, we talk about edges and green infrastructures, that have accompanied the productive landscape over the centuries and that have disappeared with mechanization. The study of land use through historical maps and past satellite images will guide the restoration of the traditional agricultural landscape, and of a better ecological condition in terms of both biodiversity and hydrogeological safety.

The planning action on the territory also becomes an important educational opportunity to understand the ambivalence of the relationships between: cause and effect, local scale and macro-scale, socio-economic and political dynamics and spatial and geographical dynamics, natural sciences, social sciences and design sciences, and much more.

\subsection{Analytical case studies.}

EU Member States have tried to respond to the challenges and opportunities facing rural areas in the 21st century by developing the EU's rural development policy: the Common Agricultural Policy (CAP) [20]. The CAP supports rural areas to cope with the wide range of economic, environmental and social challenges that such fragile systems will face. It is proposed to achieve the following strategic objectives: to foster the competitiveness of agriculture; to guarantee the sustainable management of natural resources; to structure actions to combat climate change; to achieve balanced territorial development of economies and rural communities, including the creation and maintenance of employment. EU rural development policy is implemented through rural development programs (RDPs) and through several projects focusing on resolving demographic decline and developing rural communities [20].

In the teaching process, 12 European case studies of agriculture, in line with European directives, were analyzed, mostly financed through the European Agricultural Fund for Rural Development (EAFRD), but also with national or partly regional and private contributions. Following the analysis of these case studies, it is possible to identify the two main aspects that feed rural regeneration projects. The first concerns the 
multifunctionality of agriculture, capable of providing alternative incomes and generating the conditions for choosing quality production. In this aspect also fall educational activities regarding traditional local skills, which are a cultural resource that can become the subject of courses and supplementary activities of the farm. The second aspect concerns the great abandoned heritage: the land but also the buildings. These are underutilized local resources that can fuel antifragile and resilient regeneration projects.

To undertake a specific study on the open space project, an analysis was carried out on three of these 12 companies. These three projects have interesting aspects in common in the logic and spatial structure. Most of the spaces in the cases analyzed are obviously dedicated to agricultural production, and the paths are distribution axes that connect the entire property, also becoming a public space open to visitors who explore the estate.

\subsection{Application case study.}

The territory considered as an application case study is the Italian wine landscape of Langhe-Roero Monferrato, a site recognized as a World Heritage Site since 2014 [21]. The site is located in the Piedmont region, north-west of Italy. In particular, the municipality of Vignale Monferrato is the village that was examined in the design process. The municipality of Vignale is located in the province of Alessandria, on the border with the Province of Asti. As often happens in Italy, being halfway between two large metropolises, such as Milan and Turin, it is not very accessible, far from essential services and job opportunities and in constant depopulation (Figure 1). Currently 946 inhabitants live in Vignale, of which $49.7 \%$ of the total population is over 55 years old [22]. The old age index is currently $393.5 \%$ [22].
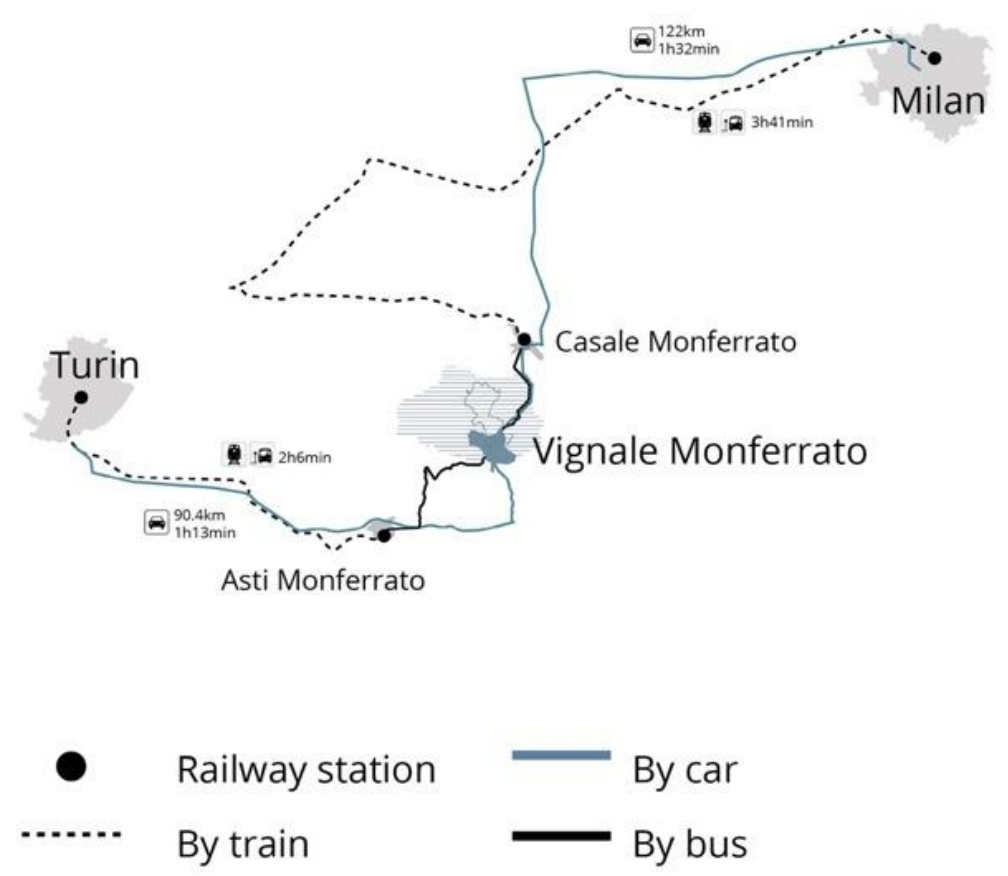

Figure 1. Location and access to Vignale Monferrato (source: Elaboration by Zhang, Zhang).

Despite this dramatic and ever-worsening picture, Vignale and its context are very rich from an environmental and cultural point of view. It is a promising heritage which, thanks also to the UNESCO recognition, is famous all over the world and represents an important opportunity, also for the surrounding area [21].

From a geographical point of view Vignale is located in the Lower Monferrato, which is a hilly area between 120 and 350 meters above sea level, near the river Po. This proximity to the river, the altitude and the hilly morphology have made the territory suitable for the cultivation of vineyards and the production of a high quality wine. 
The landscape is composed of centralized Roman and medieval settlements arranged on the ridge of the hill, with iconic buildings such as churches or castles that represent the central point of the villages and important visual references (Figure 2). A fundamental building for Vignale's identity is Palazzo Callori, home to the regional Enoteca del Monferrato, whose construction dates back to the 15th century. The Church of San Bartolomeo is located north of Piazza del Popolo, and it is an imposing building built in the 18th-19th century. The square to the west allows a view of the Monferrato hills. These building complexes of high historical and architectural value, together with the squares and streets, constitute the heart of the town and it represent the collective sense of belonging to the strong cultural identity of the area. The other residential buildings are distributed around the basic structure of the main historical settlements. There are numerous rural settlements scattered in the countryside along the road network, which follows the roads built in Roman times. The rest of the territory has wooded areas (around the settlements), meadows, vineyards and agricultural fields with arable land (Figure 3).
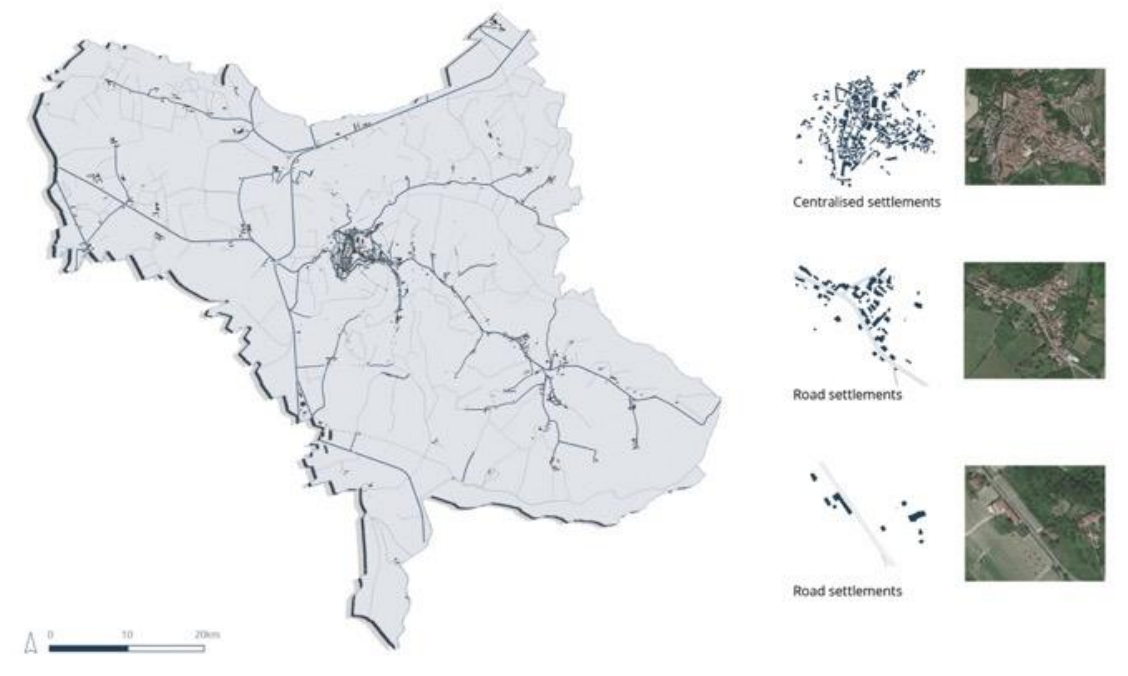

Figure 2. Settlement layout in Vignale Monferrato (source: Elaboration by Zhang, Zhang).
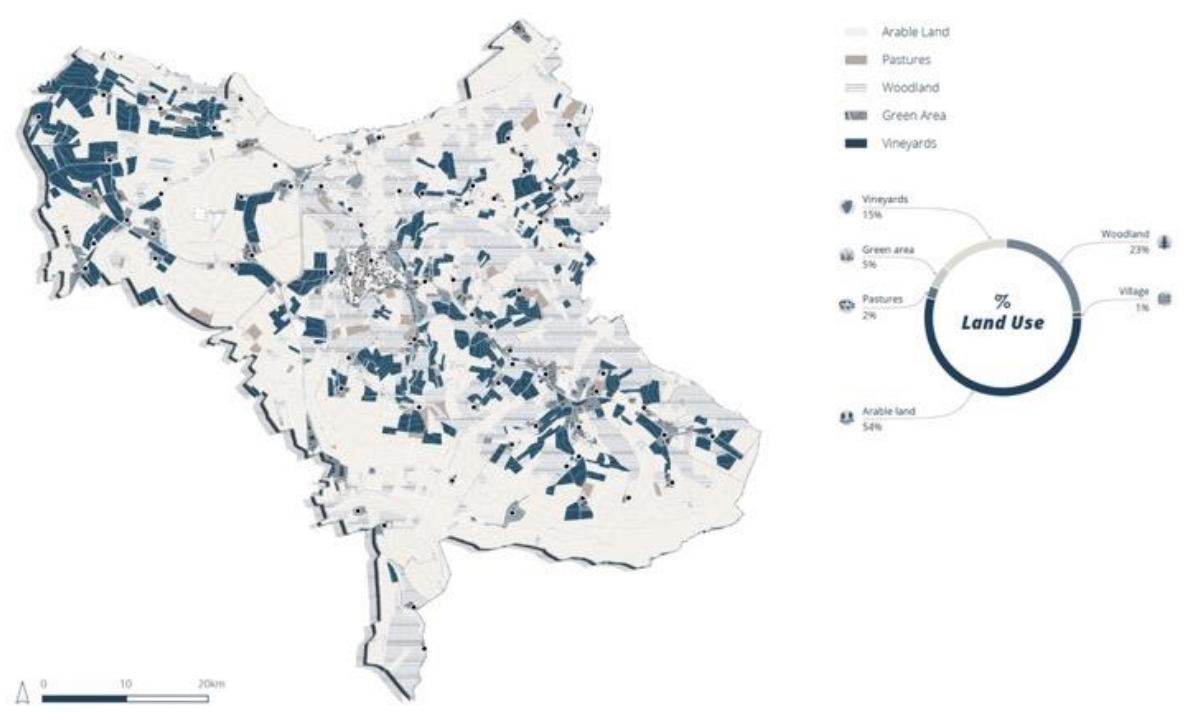

Figure 3. Land use in Vignale Monferrato (source: Elaboration by Zhang, Zhang). 
From an accommodation point of view, in addition to hotels and restaurants, the agritourism is one of the most frequent forms of hospitality and the main form of support for tourism demand, but also for the farm itself [23]. Usually surrounded by vineyards and orchards, the agritourism allows visitors to get in touch with the landscape.

The wineries are mostly located around the vineyards and are an important part of the wine production chain, as they open to the public with visits and tastings. The wine supply chain is totally on site: production, storage and distribution.

The territory assumes a fundamental social and economic role of great tourist attraction, linked not only to the production of wine but also to other typical products, such as: white truffles, a local variety of apples, red celery dating back to the seventeenth century, and others.

Tourism, here an élite and not mass tourism, is the economic response to an exceptional cultural landscape that is characterized by all the elements that revolve around agricultural production: not only the wine product itself, but also the historical artifacts and artistic activities related to agriculture, environmental quality and landscape itineraries, traditional crafts, food and wine-themed events and festivals, and much more (Figure 4).

There are also two slow paths that cross the town, but which are part of a larger system: (1) the greenway planned for the Piedmont area, and (2) a slow route that starts from Alessandria and crosses nine villages in the core area of the UNESCO site. Always in the surrounding area, there is the VENTO project: a $780 \mathrm{~km}$ cycle path funded by the Italian Ministry and designed by a research group of Milan Polytechnic, which aims at the economic regeneration of the small villages located on the Po river line [24, 25].

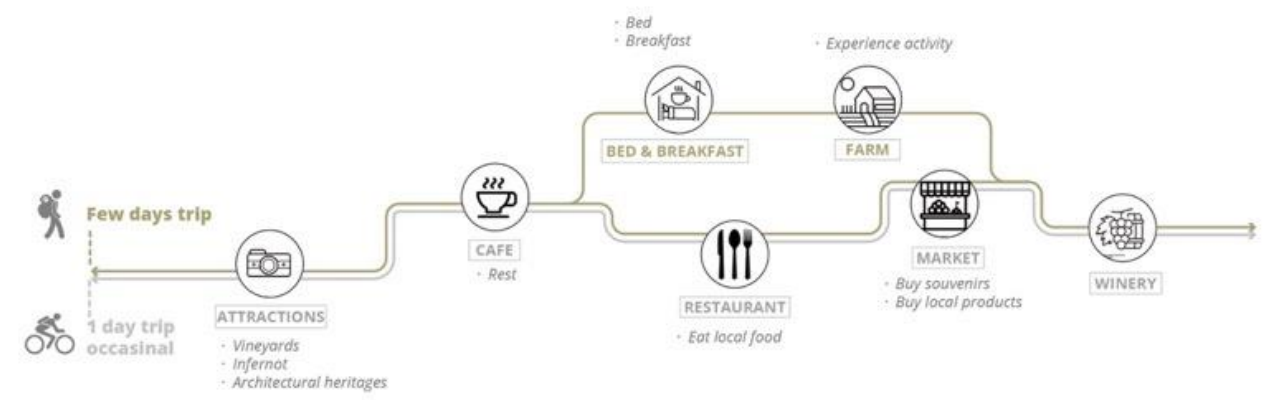

Figure 4. Existing tourism model in Vignale Monferrato (source: Elaboration by Zhang, Zhang).

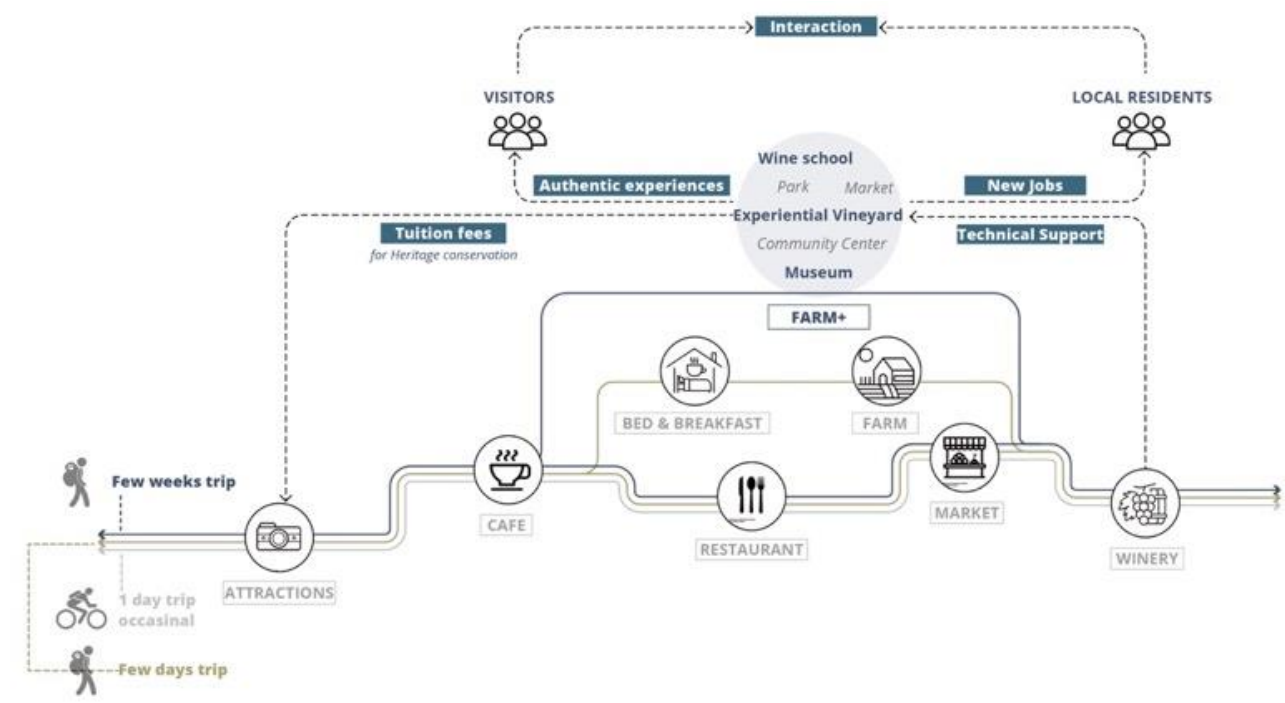

Figure 5. The proposed model for Vignale Monferrato (source: Elaboration by Zhang, Zhang). 


\subsection{The model.}

What is proposed is a multifunctional agriculture model, which integrates production income with university fees from educational courses (Figure 5). In particular, let's talk about the Farmers' Incubation Program [26]. The Farmer Incubation Program is an applied education program that aims to support the growth of new farmers. It provides new farmers temporarily with land, infrastructure and training to develop skills and start an agricultural business. These programs train young farmers on the obstacles faced by beginners starting a business: access to land and capital and the opportunities to learn and develop skills in planning agricultural activities.

To implement the model, four of these programs were selected to study their mechanisms and the amount of training fees (Pop-up garlic farmer in Melbourne; Future Growers Program in Bristol; Farm Start in Stockport; Commercial Growers Short Courses in Stockport). The courses can have very variable durations, which allows a flexible turnover of the farm. The main contents refer to the enhancement of local resources, in all their forms, and to the guidelines of the $17 \mathrm{UN}$ goals.

To undertake this model, it is possible to recover abandoned lands (previously abandoned because with a morphology difficult to cultivate) to use them with the main goal of training and education. In this way, a multifunctional area is imagined that includes production, a school of viticulture, a small museum and an agricultural park. In this sense, job places can be generated that are partly temporary (for example, internships for those who finish courses) and partly permanent. The whole project is a process of interaction and integration between the various stakeholders, between visitors and residents, between farmers and young students.

\section{Results}

Hypothesizing a scenario for the proposed model, regarding activities and flows of people, is fundamental for structuring the landscape design project. The spatial needs of a multifunctional educational farm, in a tourism context, can be summarized in three types: spaces for rest, both for guests but also open to the public outside; spaces for recreation, for events, cultural festivals, cultural exhibitions; spaces for didactics, for all type of students (brief and long time).

Two other fundamental aspects that can guide the choice of the site are: (i) the need for agricultural land to be recovered for not only productive but also training purposes; (ii) the need for a building to allocate functions that require internal space.

Starting from these needs, a site has been identified adjacent to the center of Vignale (Figure 6). The position is interesting to generate interaction with the residents and with the local economic activities. Furthermore, at this point it is possible to take the opportunity to intercept the itinerant route that start from the center of Alessandria. In this way the project would be placed in a wider regional system, and it would be possible to meet the regeneration opportunities that slow lines have always been able to offer [27, 28, 29]. The identified site is an open space of about 3.7 ha to the north-east of the town. 


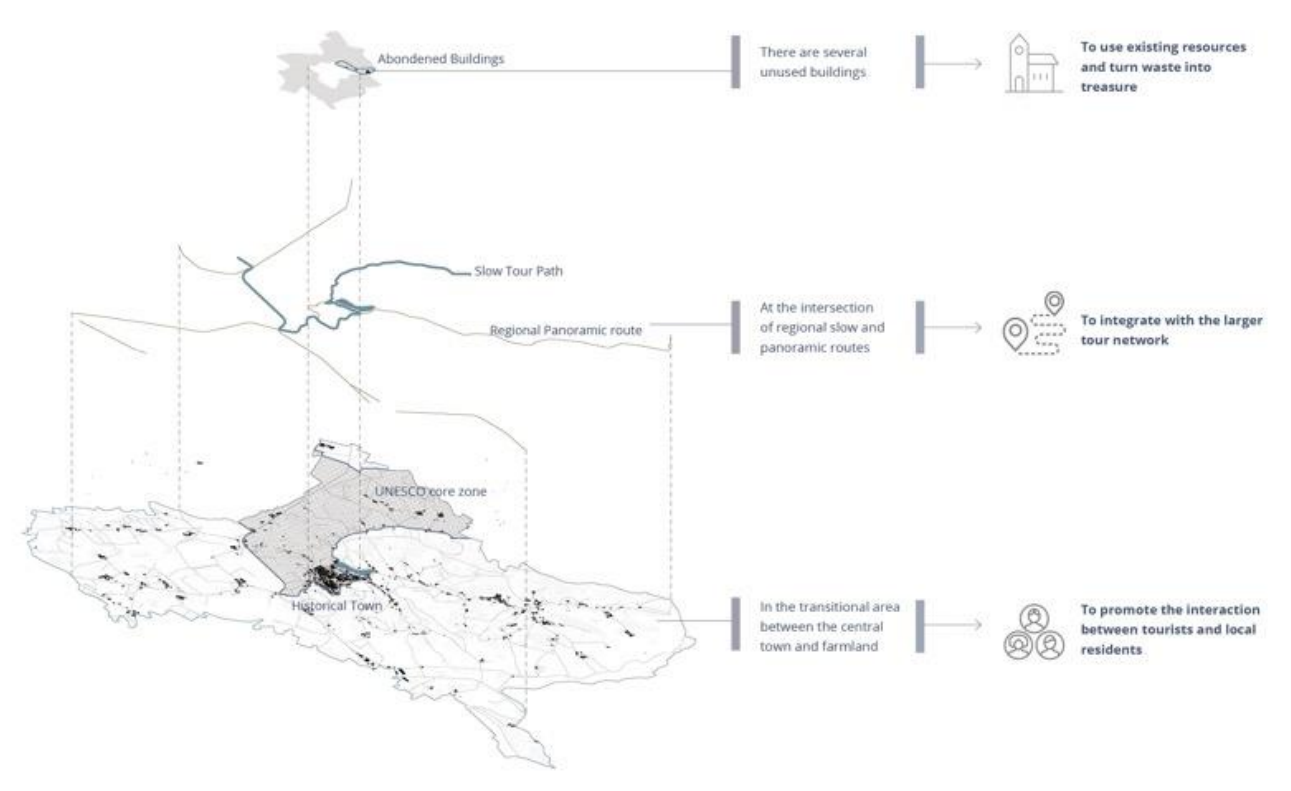

Figure 6. The site selection (source: Elaboration by Zhang, Zhang).

\subsection{Description of the project site.}

The site, located 400 meters above sea level and on a hilly area, extends longitudinally in the eastern end of the historic center and has the potential to integrate with Vignale's existing open space network. The road structure of the town is a ring, and the site is adjacent to the SP68 road. Along this road, there is a large public car park, the largest in town. There are only two bus stops in the eight villages of Core Zone 6, one of which is located less than 100 meters west of the site. Therefore, the site is easily accessible not only by car or bike, but also by public transport (Figure 7).

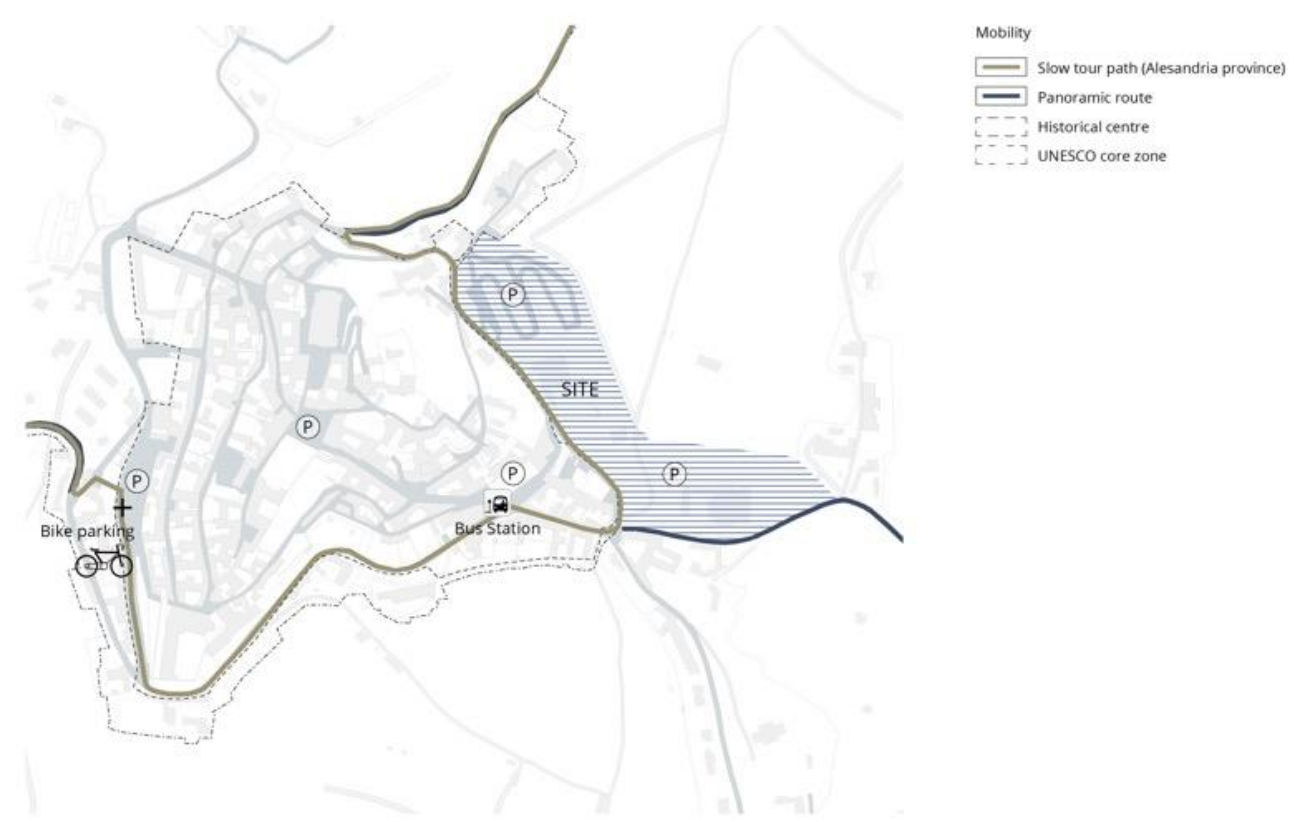

Figure 7. The relationship between site and historic town (source: Elaboration by Zhang, Zhang).

The land was of rural origin but is partially cemented. Through the study of past satellite images, it was possible to reconstruct the recent evolutionary process. In the 2001 map the northern part of the site was not a parking lot but agricultural land. Construction 
of the car park began in 2011. In addition, the vineyard on the east side of the site has turned into hazelnuts.

Comparing the situation of 2021 with that one of 2013, we can find that the pavement of the eastern car park is damaged by spontaneous vegetation.

There are four abandoned buildings on the site: a factory, two farmhouses and the Vignale winery.

\subsection{The design process.}

Assuming that the hilly slopes are a suitable place for the cultivation of quality wine grapes, especially with slopes of $10-20 \%$, it was founded the area for vineyard.

Through the analysis of the needs of the model, different types of functions were identified to be placed inside the buildings. Depending on the size of abandoned buildings and on the type of original space, the different functions will be suitably integrated.

The Cantina Sociale of Vignale, once the hub of the territory's production activity, closed in December 2011 and has been in a state of neglect for many years. It is a characterizing element, with large concrete silos, which can recall the winemaking tradition. Therefore, it lends itself to being transformed into a museum of wine culture. In addition to this, it can also host educational activities related to winemaking.

The farmhouses can be used as didactic spaces and services related to viticulture.

The factory lends itself to being transformed into reception services: accommodation, restaurant, meeting rooms, rooms for events, etc.

Once the vineyard's location and the program concerning the building's functions have been determined, the strategy of the open spaces can be examined.

There are no connecting roads between the various functional areas of the site, and it is possible to access them only separately from external roads, for this reason it is necessary to introduce a structured path within the site. Also, due to the hilly terrain, different areas of activity are at different levels of height. Therefore, a design of the connections at different height levels is necessary to facilitate accessibility for all.

To answer to these needs, it was decided to create a structured route, with new system of open spaces along it, which then becomes a functional axis that crosses the entire site, facilitating circulation and outlining the various functional areas. The new open spaces within the site become spaces of conviviality mainly serving the historic center (where some squares in the past have been transformed into parking lots and there are no open spaces for aggregation).

Regarding the environmental design project, the aim was to introduce ecological infrastructures to increase the heterogeneity of the landscape, increasing biodiversity and improving resilience of the vineyard. According to Böller et al. [30], the ecological infrastructure network is composed of three fundamental elements: large areas for permanent fauna habitats; smaller habitats that allow the accumulation of temporary animal populations; green corridor infrastructures that help animal species move between large and medium-sized habitats. It is estimated that the optimal area of ecological infrastructure for a production site, to ensure adequate diversity of species, is close to 15\% [30]. According to the International Organization for Biological and Integrated Control (IOBC), a minimum of $5 \%$ of agricultural land must be used for ecological infrastructure [31]. With this goal, trees and large shrubs of the site were kept to create a natural green space as a biodiversity hotspot on the perimeter of the vineyard. Rows of trees and shrubs are planted along the roads and the edges of the fields, which therefore act as connecting corridors between ecological areas. Areas of linear elements and non-linear elements are put into a system with the aim of generating a diverse and rich landscape in terms of biodiversity (Figure $8)$. 


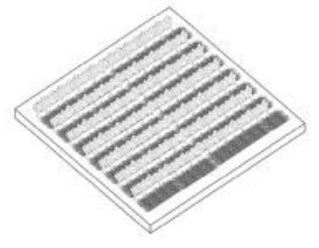

natural and seminatural grassland

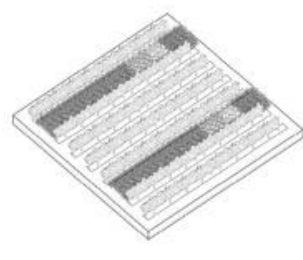

wildflower strips

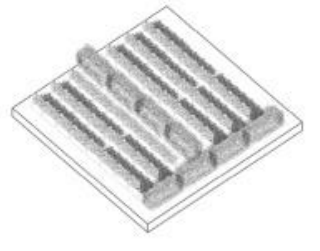

Interspersing hedges with the vines

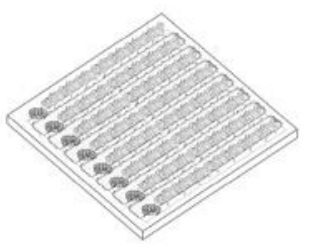

Planting shrubs at the ends of each row

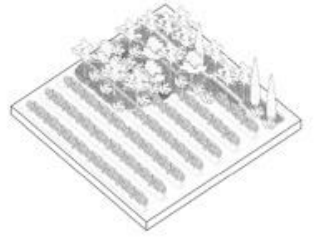

The provision of compensatory areas

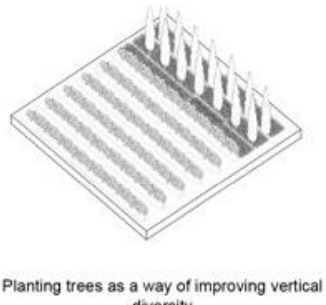

diversity

Figure 8. Strategies to improve biodiversity in the vineyard (source: Elaboration by Zhang, Zhang).

Parallel to the ecological infrastructures, a network of slow paths has been imagined. The corridor inside the site can become a possible extension of the external path, equipping it with shaded stops and bicycle parking. The corridor is divided into two parts: east and west. On the sloping site, to the west, a system of platforms was created to connect nodes, with inclinations adapted to allow accessing by cyclists and people with reduced mobility (Figure 9).
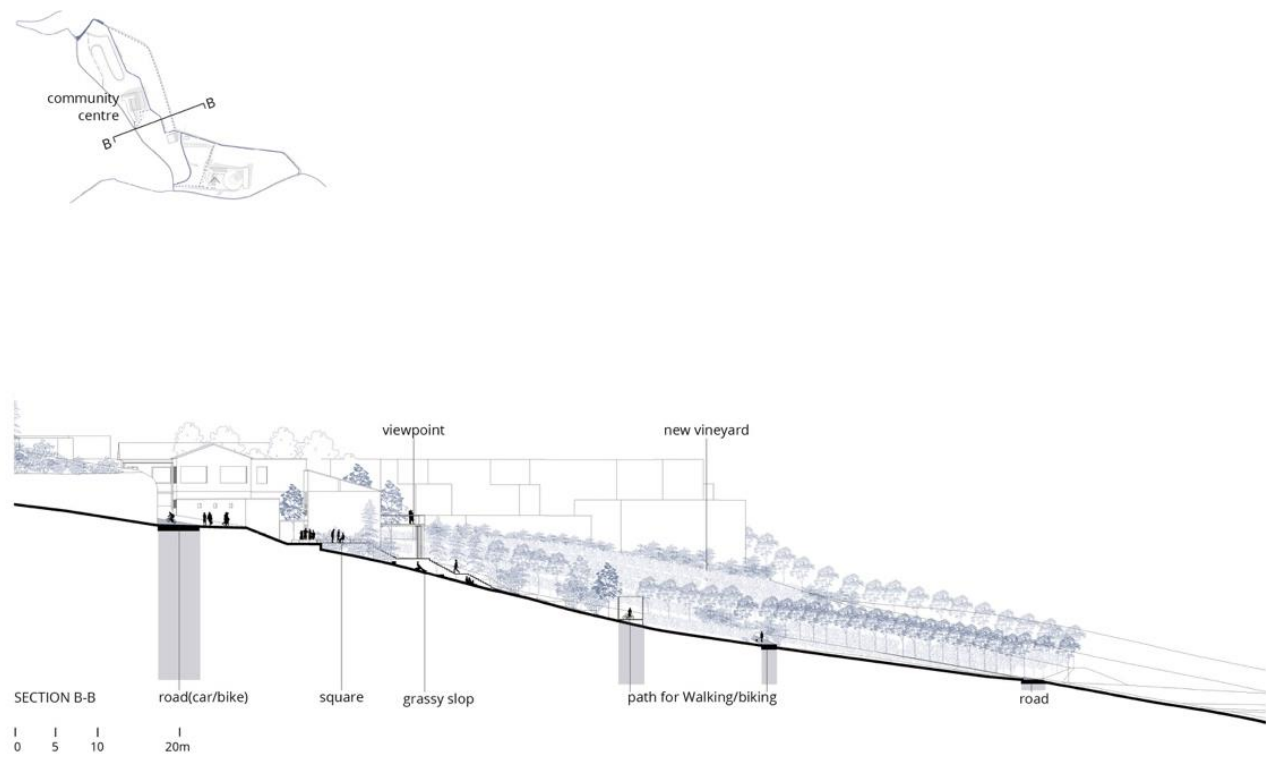

Figure 9. A section of the sloping site, with the system of platforms (source: Elaboration by Zhang, Zhang).

The entire rural space is conceived as a public park, integrated with the existing village, and ready to host anyone. In particular, the Wine Park is a multifunctional area obtained from the previous parking lot, flexible and suitable for hosting various events. 


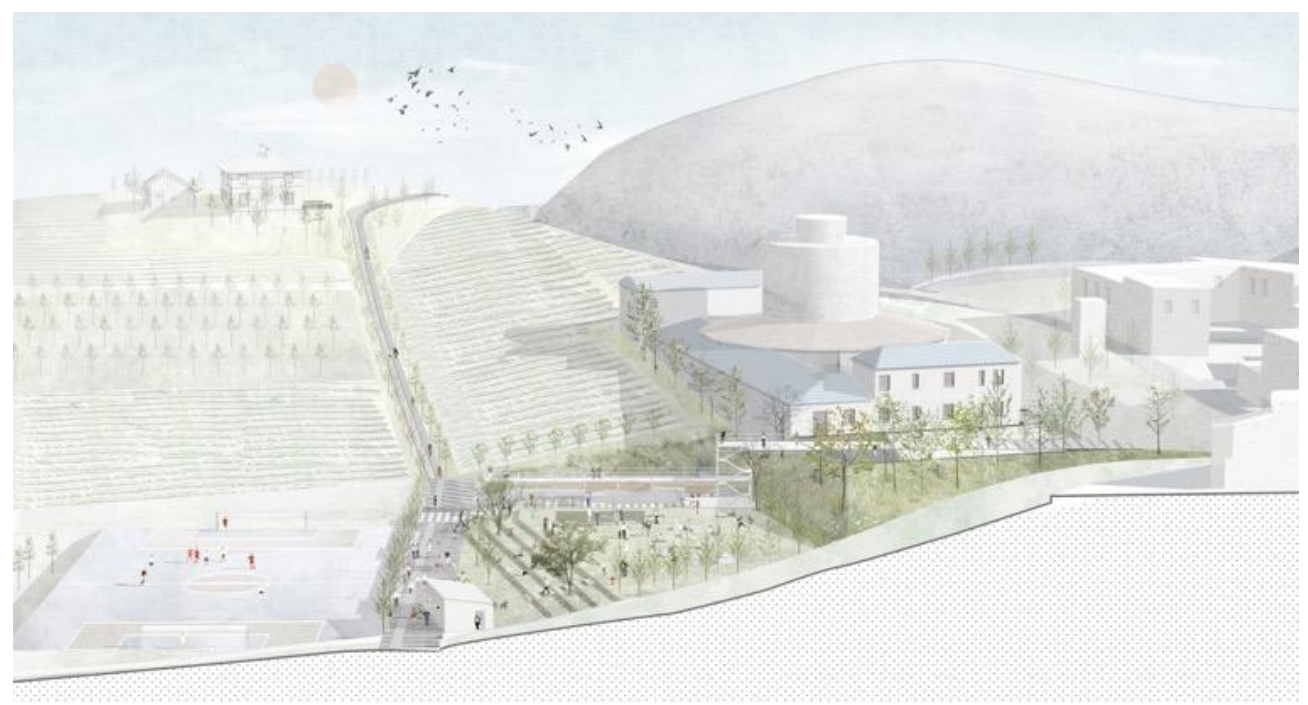

Figure 10. A view of the Wine Park (source: Elaboration by Zhang, Zhang).

The wine school can provide students with three types of courses of different duration (from two days to nine months). Among them, only students with a long course duration receive accommodation. The other two types of students can rely on accommodation provided in the village (small hotels or airbnb), which can benefit local economy. Tuition can be used as a stable source of income to help the project sustain itself. In the short term, the goal is to provide jobs for the locals through school, museum and other activities. The long-term goal is to attract students interested in wine production. A total of 30-36 students can be accommodated.

\section{Discussion}

The following work explores the potential of the landscape design project in improving resilience of a rural area. In undertaking the work, two integrated paths have been developed: the masterplan (Figures 11 and 12) of an innovative agriculture, which becomes a place of education but also a public space integrated into the existing system, and the model of a multifunctional agriculture, oriented towards teaching and tourism. This model does not want to deny the original productive identity of agriculture but to track down additional possibilities for maintaining the rural vocation, acting as an attractor for revitalization and rural enhancement of the territory.

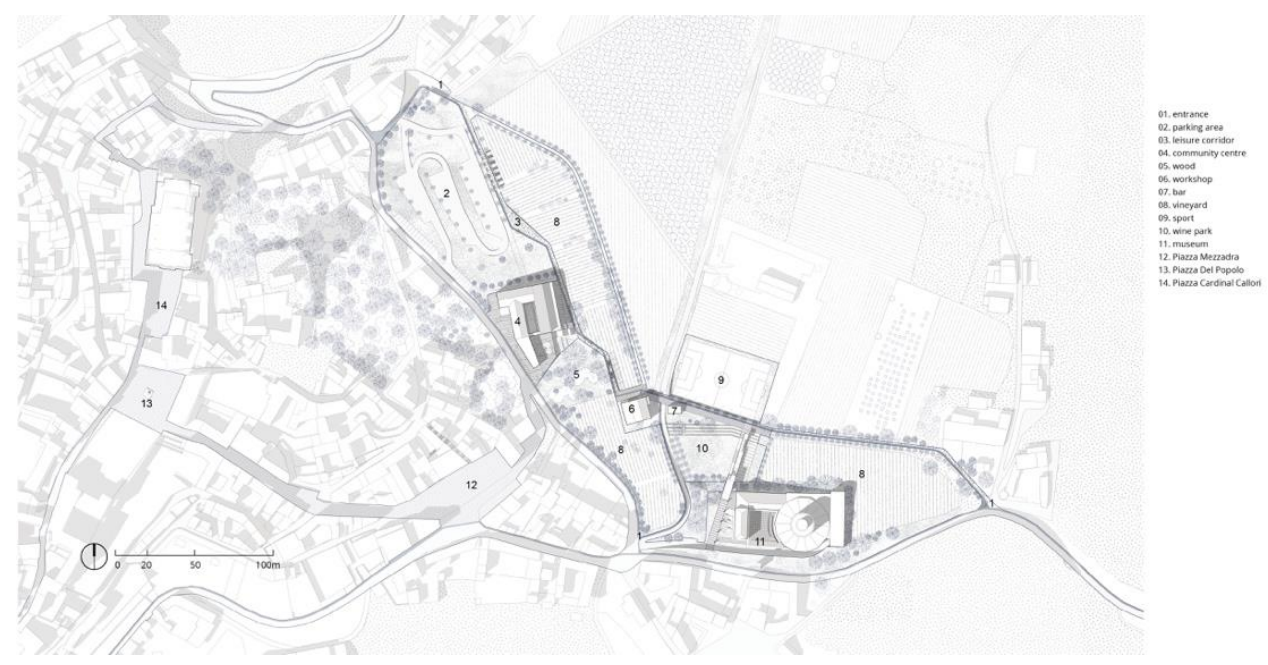

Figure 11. The masterplan proposed (source: Elaboration by Zhang, Zhang). 


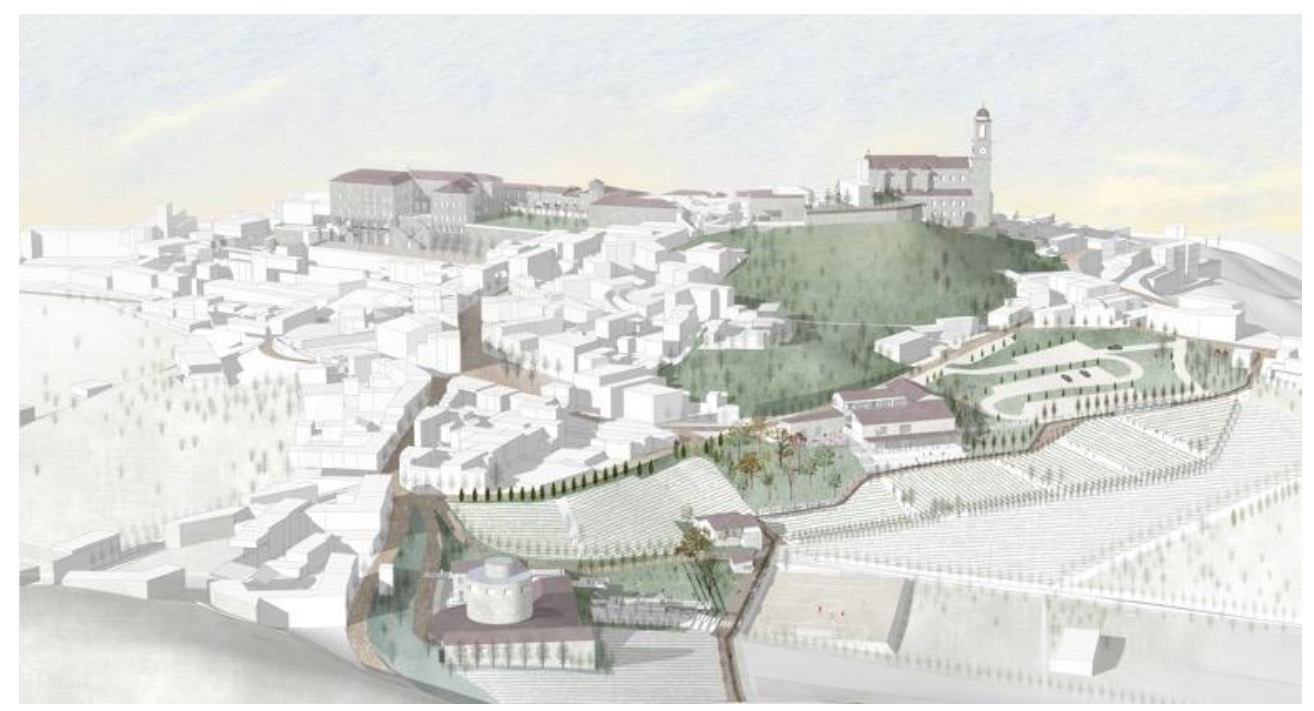

Figure 12. A view of the masterplan proposed (source: Elaboration by Zhang, Zhang).

The project takes Vignale Monferrato as an application case, converting 3.7 hectares of unused land into a multifunctional farm, with a wine school, a museum of wine culture, and leisure spaces open to all.

The model could provide eight new jobs and the wine school could accommodate up to 36 students in long-term courses. At the start of the project, tuition fees for education courses are used as a source of income. As other functions are improved, the tourism brand is established and attracting more tourists. The new revenues can be invested in the conservation of the cultural heritage and in the revival of the village.

The rural villages' revitalization and the heritage's conservation are universal issues that affect all rural systems in the world, which is why the aim of this study is to find measures that can be replicated on other territories. From the planning point of view, it is possible to draw many aspects of replicability concerning: the network of open spaces, as the rural space has the possibility of being a public space; the infrastructure of slow paths, which has the ability to generate local and supra-local systems; green networks integrated into the productive landscape, which can increase biodiversity and restore the original historical image of rural areas.

If the model develops successfully, it can achieve the stability and continuity of the cultural landscape over time.

\section{Conclusions}

The problem of depopulation of rural systems on a global scale puts at risk the varied and rich rural heritage and the environmental systems that host it $[15,16]$. But it's in this heritage at risk, we can be able to find one of the cornerstones of the territorial rebirth of a vast part of our countries. In this sense, we see the abandonment as not a final state, but as an intrinsic opportunity for a second beginning [32].

Coherent to this concept, the main objective for European cohesion policies, such as SNAI in Italy [17], is the reversal of the demographic trend of these territories and it is pursued through two classes of actions: (i) the first focuses on adjusting the offer of essential services, so that means the preconditions for the territorial development; (ii) the second aims to implement interventions in favor of local development, focused to generate labor demand through the re-use and enhancement of territorial capital. Precisely in this last class of actions there are tools that solicit the enhancement of resources through quality actions with low environmental impact.

The different forms of sustainable tourism (slow tourism, green tourism, rural tourism, ecotourism, etc.) can be the appropriate action for this type of strategy [23, 27, 29]. 
Today farm is changing towards new forms of business, through the development of activities that add value to products (ISMEA, 2016): this means talking about the agricultural multifunctionality of the business [33]. In the OECD definition, multifunctionality is related to the joint presence of both the ability of agriculture to produce food goods, as well as secondary goods and services, of a tangible and intangible nature, thus carrying out a social, cultural and environmental function, as well as a productive one [33].

The protection and regeneration of cultural and fragile landscapes, therefore, must be an intentional orientation of policies, but it can be implemented thanks to a landscape design project intervention, which keeps productivity active through a multifunctional vision of agriculture. In this sense, here the didactic process was useful to understand how a pioneering vision can be implemented thanks to an exploratory investigation and research process, that takes the form of a cognitive act also in its design development (research-by-design). Once again, it is a question of multidisciplinarity, skills and horizontality of local governance.

It is with these assumptions, which deconstruct rhetorical premises and orient different knowledge to a single project understood as a research process, that the intervention in the rural landscape can be catalyst of biunivocal dynamics of conservation and innovation and of resilience and antifragility.

Author Contributions: Conceptualization, C.D..; methodology, C.D.; data collection, C.Z., Y.Z.; data curation, C.D., C.Z., Y.Z.; writing-original draft preparation, C.D.; writing-review and editing, C.D.; supervision, C.D.

D.M. was involved in consolidating the point of view regarding resilience of cultural rural landscapes, across the entire paper.

C.Z. and Y.Z. produced all the images and maps.

All authors have read and agreed to the published version of the manuscript.

Funding: This research received no external funding.

Acknowledgments: The authors would thank the colleague Dr. Mario Paris, co-supervisor of the thesis described.

Conflicts of Interest: The authors declare no conflict of interest.

\section{References}

1. World Heritage Convention, 1992. Available online: https://whc.unesco.org/en/convention/ (Accessed: 26-07-2021).

2. Salter, C. The cultural landscape; Publisher: Duxbury Press, Pacific Grove, 1971.

3. Piccardi, S. Il paesaggio culturale; Publisher: Patron Editore, Bologna, 1986.

4. Piccardi, S. Il paesaggio culturale in geografia; Publisher: Patron Editore, Bologna, 1987.

5. Andreotti, G. Paesaggi culturali. Teoria e casi studio; Publisher: Unicopli, Milano, 1996.

6. Andreotti, G. Alle origini del paesaggio culturale. Aspetti di filologia e genealogia del paesaggio; Publisher: Unicopli, Milano, 1998.

7. Barbera, G.; Biasi, R.; Marino, D. I paesaggi agrari tradizionali. Un percorso per la conoscenza; Publisher: FrancoAngeli, Milano, 2014.

8. Dezio, C. Paesaggi agrari resilienti. Approcci e metodi per l'analisi di pratiche processi e strategie territoriali; Publisher: FrancoAngeli, Milano, 2020.

9. Gulinck, H.; Wagendorp, T. References for fragmentation analysis of the rural matrix in Cultural Landscapes. Landscape and Urban Planning 2002, vol. 58 (2- 4), 137-146.

10. Palang, H.; Alumae, H.; Antrop, M.; Helmfrid, S. Rural Landscapes: past processes and future strategies. Landscape and Urban Planning 2005, vol. 70 (3-8), 3-8.

11. Rescia, A.; Willaarts, B.; Schmitz, M.; Aguilera P. Changes in land uses and management in two nature reserves in Spain: evaluating the social-ecological resilience of cultural landscapes. Landscape and Urban Planning 2010, vol. 98 (1), $26-35$.

12. Solymosi, K. Indicators for the identification of cultural landscape hotspots in Europe. Landscape Research 2011, vol. 36 (1), 3-18.

13. Dezio, C.; Cavallo, A.; Marino, D. Resilient agrarian landscapes in face of changes: the coevolutive approach to understand the links between communities and environmental characters. In Biocultural diversity in Europe; Agnoletti, M.; Emanueli, F.; Publisher: Springer, 2016.

14. Dezio, C.; Marino, D. A reading model for Resilience in Terraced Wine Landscape. In Terraced Landscapes: choosing the future; Alberti, F.; Dal Pozzo, A.; Murtas, D.; Salas, M.A.; Tillmann, T.; Publisher: Regione Veneto, 2018.

15. Rey Benayas, J.M.; Martins, A.; Nicolau, J.M.; Schulz, J.J. Abandonment of agricultural land: an overview of drivers and consequences. CAB Reviews: Perspectives in Agriculture, Veterinary Science, Nutrition and Natural Resources, 2007, no. 057. DOI: https://doi.org/10.1079/PAVSNNR20072057. 
16. De Rossi, A. Riabitare l'Italia. Le aree interne tra abbandoni e riconquiste; Publisher: Donzelli Editore, Roma, 2018.

17. SNAI. Strategia Nazionale per le Aree Interne. Available online: http://www.programmazione economica.gov.it/2019/05/23/strategia-nazionale-delle-aree-interne/. (Accessed on 14-12-2019).

18. Zhang, C; Zhang, Y. Design with Landscape. An experimental model towards a goal of resilience in Vignale Monferrato. Thesis of master's degree, Landscape Architecture Degree Course, Polythecnic of Milan, Italy. Discussed on July $23^{\text {rd }}, 2021$.

19. Waldheim, C. The landscape urbanism reader. Publisher: New York, Princeton Architectural Press, 2006.

20. Common Agricultural Policy. Available online: https://ec.europa.eu/info/food-farming-fisheries/key-policies/common-agricultural-policy_en (Accessed 26-07-2021).

21. Langhe-Roero Monferrato UNESCO. Available online: https://whc.unesco.org/en/list/1390/ (Accessed: 26-07-2021).

22. ISTAT data. Available online: https://www.istat.it (Accessed: 26-07-2021)

23. Dezio, C. Agritourisms and slow lines: hybrid practices for a landscape design model to support agriculture of mountain regions. The Vermont case reading from Italian perspective. Ciudades, 2021, vol. 24, 79-98.

24. VENTO project. Available online: http://www.cicloviavento.it (Accessed: 26-07-2021).

25. Pileri, P.; Giacomel, A.; Giudici, D. VENTO. La rivoluzione leggera a colpi di pedale e paesaggio; Publisher: Corraini Edizioni, Mantova, 2015.

26. Agudelo Winther, E.; Overton, M.; Heron, C. The Farm Incubator Toolkit: Growing the Next Generation of Farmers. Developed by the National Incubator Farm Training Initiative (NIFTI); Publisheer: The New Entry Sustainable Farming Project (New Entry), 2013. Available online: https://nesfp.org/sites/default/files/uploads/nifti_toolkit_v2.pdf (Accessed: 16-07-2021).

27. Dezio, C. A bioregional reading of the rural landscapes of the Italian inner areas and the regerative potential of rural tourism. The case study of the VENTO project. Ciudades, 2020, vol. 23, 46-69.

28. Pileri, P. Progettare la lentezza. Publisher: People, Busto Arsizio (VA), 2020.

29. Pileri, P.; Moscarelli, R. Cycling \& Walking for Regional Development. How slowness regenerates marginal areas. Publisher: Springer, 2021.

30. Boller, E.F.; Häni, F.; Poehling, H.M. Ecological Infrastructures. Ideabook on Functional Biodiversity at the Farm Level. Publisher: IOBCwprs Commission on Integrated Production Guidelines and Endorsement, 2004.

31. Stefanucci, S.; Graça, A.; Novello, V.; Belda, I.; Carlos, C.; Gautier, J. OIV COLLECTIVE EXPERTISE FUNCTIONAL BIODIVERSITY IN THE VINEYARD, 2018. Available online: https://www.oiv.int/public/ medias/6367/functional-biodiversity-in-thevineyard-oiv- expertise-docume.pdf (Accessed: 26-07-2021).

32. Dezio, C. Abandonment I Territorial Fragilities in Territorial Fragilities in Italy. Defining a Common Lexicon. Territorio, 2020, vol. 91, 25-26.

33. OECD Multifunctionality. Towards an analytical framework. Publisher: OECD Publications Service, 2001. 